Industrial Relations Section

Princeton University

Working Faper \#121

April 1979

Education, Unemployment, and Earnings

by

Orley Ashenfelter*

John Ham*

Princeton University

* The authors are indebted to Robert E. Lucas, David Metcalf, Sherwin Rosen, and seminar participants at Princeton University and the University of California, at San Diego, for helpful comments. Ham's research was generously supported by the Canada Council. 
Education, Unemployment, and Earnings

Orley Ashenfelter and John Ham

\begin{abstract}
Using data on adult male workers we first investigate the incremental effect of a year of schooling on unemployed hours, and use this calculation to explain the difference in the proportional effects of schooling on earnings and wages. Schooling apparently reduces unemployed hours by reducing the incidence of unemployment spells, but it does not significantly affect their duration. We next test whether unemployed hours represent real constraints on worker behavior. To do this we develop and estimate life-cycle models of labor supply for workers with and without spells of unemployment using longitudinal data. The results imply that perhaps three-quarters of the unemployed hours of male workers are part of the offer to sell labor.
\end{abstract}




\section{Education, Unemployment, and Earnings}

by

Orley Ashenfelter and John Ham*

Princeton University

It is widely known that unemployment rates are inversely related to the educational attainment levels of workers. In the 1970 U.S. Census, for example, the unemployment rates of males without, with, and with more than a high school degree were $5.3,2.8$, and 1.4 percent, respectively. To the extent that unemployment represents a constraint on choice as opposed to an element of it, and to the extent that additional schooling is responsible for real reductions in these constraints, educational investments have an impact on more than the income received from an hour spent at work. In this paper we open an investigation of both of these issues. In the first section of the paper we examine the extent to which education and experience reduce the unemployed hours of workers and calculate the effect this has in increasing worker earnings. In the second part of the paper we attempt to test for whether workers perceive the unemployment they report as real constraints on choice.

Our motivation for the analysis is twofold. First, it has become a widely observed fact that an incremental year of schooling has a proportional effect on the earnings of male workers that is greater than its proportional effect on wage rates. I/ This indicates that both the wage rate and hours at

* The authors are indebted to Robert E. Lucas, David Metcalf, Sherwin Rosen, and seminar participants at Princeton University and the University of California, at San Diego, for helpful comments. Ham's research was generously supported by the Canada Council. I/See Mincer (1974) for evidence from the U.S. and PsacharopouIos and Layard (1977) for Britain. 
work increase with schooling level. The latter may occur either because labor supplied to the market increases with schooling level, or, to the extent that it reflects a constraint on choice, unemployment decreases with schooling level. Since increased schooling is known to increase wage rates it might be thought that this indirect effect of schooling on labor supply through the wage rate accounts for the positive correlation between schooling and hours worked. Most estimates of male labor supply parameters provide very little evidence of a positive effect of wage rates on labor supply, however, and many estimates suggest the relationship may be negative, so that this explanation seems tenuous. In the first section of the paper we take measured estimates of unemployed hours at face value and simply determine whether the effect of schooling on unemployed hours can account for the larger effect of schooling on earnings than on wage rates.

There is, however, a far more difficult issue involved in the correlation between schooling and unemployment. As aggregate unemployment rates have become permanently higher in many countries it is now fashionable to question the extent to which this may be attributed to more fundamental shifts in the structure of the labor force. In most discussions of this issue in the U.S. it is observed that several groups with historically high unemployment rates, including particularly female and younger workers, have become a larger proportion of the work force in recent years. It is often concluded that this implies that the "permanent" or "natural" rate of unemployment has increased. At the same time, the educational attainment of workers has also increased and most simple calculations actually imply that these demographic and educational effects taken together would tend to reduce the permanent rate of unemployment. Of course, none of these calculations is based on a well specified model of the determinants 
of the permanent unemployment rate, and we do not offer one here. Nevertheless, it is important to determine whether the reduced unemployed hours resulting from educational attainment represent a perceived constraint on choice since, if they do not, it can hardly be argued that greater educational investments have reduced the permanent unemployment rate. We return to this issue in the second section of the paper.

\section{Education and Unemployment}

If unemployed hours are taken at face value then labor supply $h^{*}$ is simply $h^{*}=h+u$, the sum of employed $(h)$ and unemployed $(u)$ hours. With the wage rate $w$, desired earnings are then

$$
w^{*}=w h(1+u / h)
$$

and the logarithm of observed earnings is approximately

$$
\text { (1) } \quad \operatorname{lnwh}=\operatorname{lnwh}^{*}-(\mathrm{u} / \mathrm{h}) \text {. }
$$

It follows immediately that if $\operatorname{lnh}^{*}$ is independent of schooling (s), then

$$
\text { (2) } \partial \ln (w h) / \partial s-\partial \ln w / \partial s=-\partial(u / h) / \partial s \text {. }
$$

In fact, taking the logarithm of earnings, the wage rate, $u / h$, and $h^{*}$ to be linear regression functions of schooling and experience $(x)$ and its square in the form

$$
\text { (3) } y_{i}=\alpha_{0 i}+\alpha_{1 i} s+\alpha_{2 i} x+\alpha_{3 i} x^{2}+\varepsilon_{i} \quad(i=1, \ldots, 4)
$$

where $y_{i}$ represents $\ln (w h), \ell n w, u / h$, and $l n h^{*}$, respectively, as $i=1,2$, 3, 4, implies that the least squares estimates of (3) will satisfy exactly the 
relationship

$$
\text { (4) } \hat{\alpha}_{j 1}-\hat{\alpha}_{j 2}+\hat{\alpha}_{j 3}=\hat{\alpha}_{j 4} \quad(j=0,1,2,3) \frac{2 /}{6}
$$

In this setup the difference between the effect of schooling on earnings and wage rates is $\hat{\alpha}_{11}-\hat{\alpha}_{12}$ and may result either from the effect of schooling on unemployment, $-\hat{\alpha}_{13}$, or from the effect of schooling on labor supply, $\hat{\alpha}_{14}$. Likewise, the same breakdown may be carried out for any of the other variables in equation (3). If we find that $\hat{\alpha}_{11}-\hat{\alpha}_{12}=-\hat{\alpha}_{13}$, then the excess of the effect of schooling on earnings over its effect on wage rates is entirely a result of its effect in reducing unemployment. Equivalently, finding that $\hat{\alpha}_{11}-\hat{\alpha}_{12}+\hat{\alpha}_{13}=0$ implies that schooling does not affect measured labor supply. A precisely analogous analysis of the effects of experience on earnings and wages is implied by equation ( 3 ).

Table 1 contains the results of fitting equation (3) to the 8-year averages of data on 799 white males drawn from the longitudinal data of the University of Michigan Income Dynamics Survey (IDS). The sample contains all white males from the randomly drawn half-sample with positive hours of work in each of the eight years from 1967 to 1974 who were aged between 25 and 50 in 1967. The mean school years completed for these workers was 12.4 and they had a mean of 19.2 years of experience in 1967, where experience is defined in the conventional way as the difference between age and estimated age at school leaving $(s+6)$. Other sample statistics are contained in appendix table A-1.

2/ If the error terms are normally distributed the least squares estimates will also be the maximum likelihood estimates. 


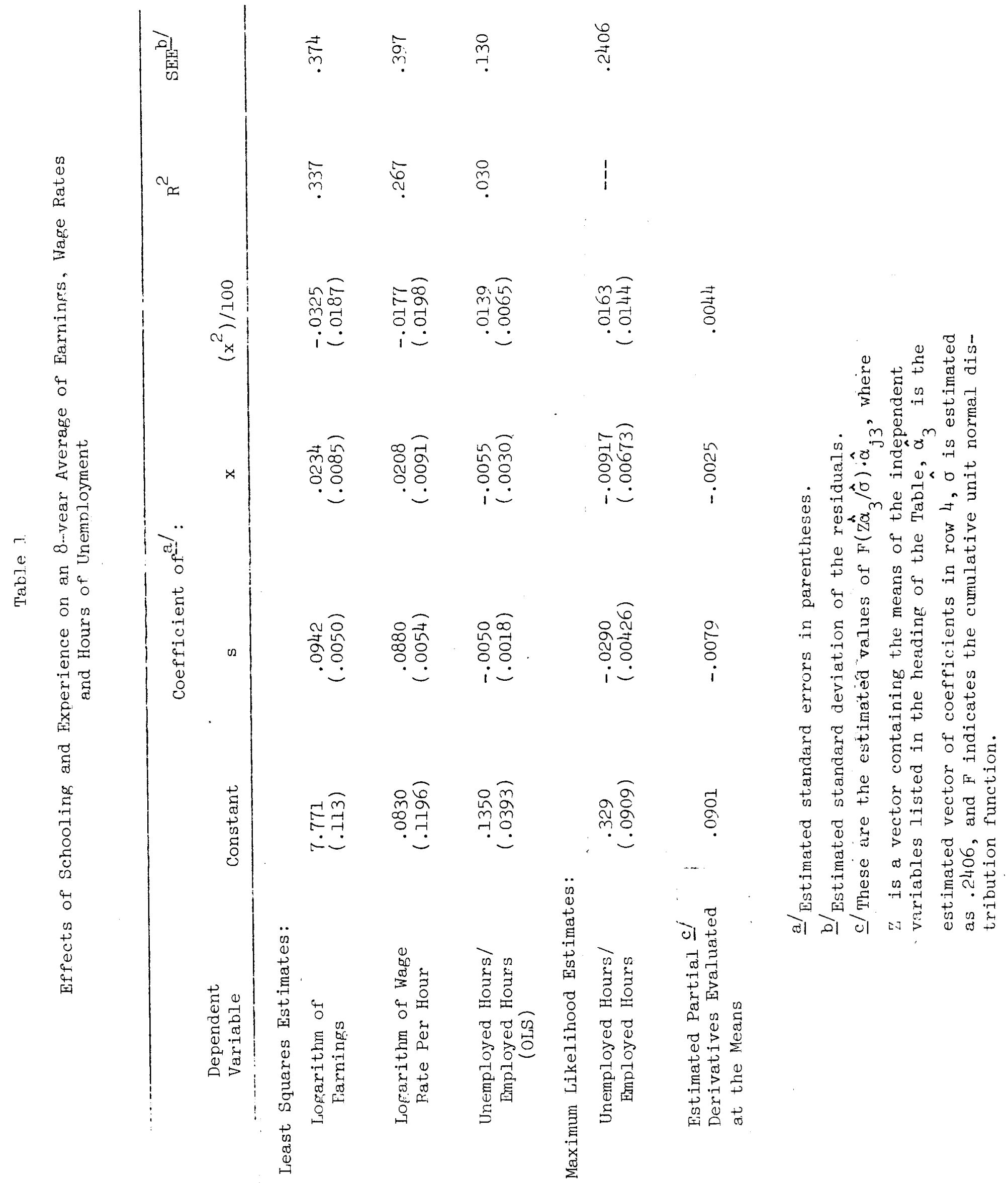


Our purpose in fitting equation (3) to the 8-year averages of the data is twofold: First, these results serve as a convenient summary of the more detailed year-by-year results in Table 2. Second, the average results represent a relationship that spans a full business cycle. As can be seen from Table 3, 1967-69 were low unemployment years for this group while 1970-71 were not. Likewise, the low unemployment of 1972-73 was followed by the very beginning of the recession that started in 1974 .

As can be seen from the Table the effect of an extra year of schooling on $\log$ earnings is .0062 or seven percent greater than its effect on log wages. As can also be seen from the Table the least squares estimate of the effect of an extra year of schooling on unemployment is -.005 and accounts for 81 percent of the discrepancy. In fact, the effect of schooling on unemployment is highly statistically significant while the implied effect of schooling on labor supply is not. Thus, the hypothesis $\alpha_{11}-\alpha_{12}+\alpha_{13}=0$ cannot be rejected, implying that from a statistical point of view the hypothesis that the effect of schooling on unemployment accounts for all of the discrepancy between the effect of schooling on earnings and wage rates cannot be rejected either. $3 /$

Table 1 also indicates similar results for the effect of experience on unemployment. Again, the effects of $x$ and $x^{2}$ on earnings are larger (in absolute value) than the effects of these variables on wage rates. Within sampling errors virtually all of this discrepancy is again accounted for by the effect of experience on unemployment. Consequently, the hypotheses $\alpha_{j 1}-\alpha_{j 2}+\alpha_{j 3}=0$ for $j=2,3$ also cannot be rejected. This has important

3/ It should be noted that we are not arguing that schooling as, say, a taste variable has no structural effect on labor supply. Schooling may affect labor supply both indirectly through the wage and directly as a taste variable in an equation where the wage is held constant. The result in the text implies only that the sum of these effects is small. 
implications for the study of life-cycle profiles. In particular, the results in Table $I$ imply that the log wage peaks at $\hat{x}=58$, which is well outside any observation in the sample and is virtually the age at retirement or beyond for all workers. On the other hand, log earnings peak at $\hat{x}=36$ which is very much earlier. The difference, of course, is due to the fact that unemployment reaches its minimum at around $\hat{x}=20$ and consequently tends to cause $10 g$ earnings to peak earlier than would otherwise be the case. The upshot is that measured labor supply is virtually independent of potential experience in this sample.

Up to this point we have ignored the fact that $u / h$ is truncated at zero and that a maximum likelihood procedure that recognizes this may be a more appropriate estimation scheme. Consequently, the results of estimating the determinants of $u / h$ by a well known method suggested by Tobin (1958) have also been placed in Table 1. The estimate of the effect of schooling on unemployed hours is now -.0079 , which is reasonably close to the least squares estimate of $\partial(u / h) / \partial s$ and is quite close to the differential effect of schooling on wages and earnings of -.0062 . Assuming that unemployment hours follow a trun-cated normal distribution does lower the impact and significance of experience and experience squared on hours of unemployment as the Table indicates.

Since most analyses of the effect of schooling and experience on earnings and wage rates use a single cross-section for the analysis, in Table 2 we report the results for the schooling coefficients from fitting equation (3) to the data for each of the eight years. Although none of our basic conclusions need be altered, as can be seen from the Table, these coefficients are not entirely stable from year to year. Although most of the coefficients on schooling in the least squares unemployment equations are within sampling errors of each 
Table 2

Estimated Effects ${ }^{\text {al }}$ of Schooling on Earnings, Wage Rate and Unemployment Hours 1967-1974

\section{Effect on:}

$\begin{array}{ccc} & u / h \\ & u / h & \text { Tohit: } \\ \text { Earnings } & \text { Wage } & F\left(\frac{Z}{Q_{3}}\right) \cdot \hat{\alpha} b / \\ \frac{g}{13}\end{array}$

(1)

(2)

(3)

(4)

(1) $-(2)$

\begin{tabular}{|c|c|c|c|c|c|}
\hline 1967 & $.0912^{*}$ & $.0890 *$ & -.00678 & $-.0017^{*}$ & .0022 \\
\hline 1968 & $.0935 *$ & $.0885 *$ & $-.00457 *$ & $-.0039 *$ & .0050 \\
\hline 1969 & $.0948 *$ & $.0875 *$ & $-.00481 *$ & $-.0038 *$ & .0073 \\
\hline 1970 & $.0962 *$ & $.0917^{*}$ & $-.00498 *$ & $-.005 *$ & .0045 \\
\hline 1971 & $.0963^{*}$ & $.0902 *$ & .00129 & $-.021^{*}$ & .0061 \\
\hline 1972 & $.0919 *$ & $.0895^{*}$ & $-.00281 *$ & $-.0038 *$ & .0024 \\
\hline 1973 & $.0910 *$ & $.0829^{*}$ & $-.00524 *$ & $-.005 *$ & .0081 \\
\hline 1974 & $.0988 *$ & $.0844 *$ & $-.0120^{*}$ & $-.0116 *$ & .0144 \\
\hline Samole Means & $.0942 *$ & $.0880^{*}$ & $-.00498 *$ & $-.0079 *$ & .0062 \\
\hline
\end{tabular}


Table 3

Incidence and Mean Duration of Unemployment Hours Relative to Employment Hours, 1967-1.974

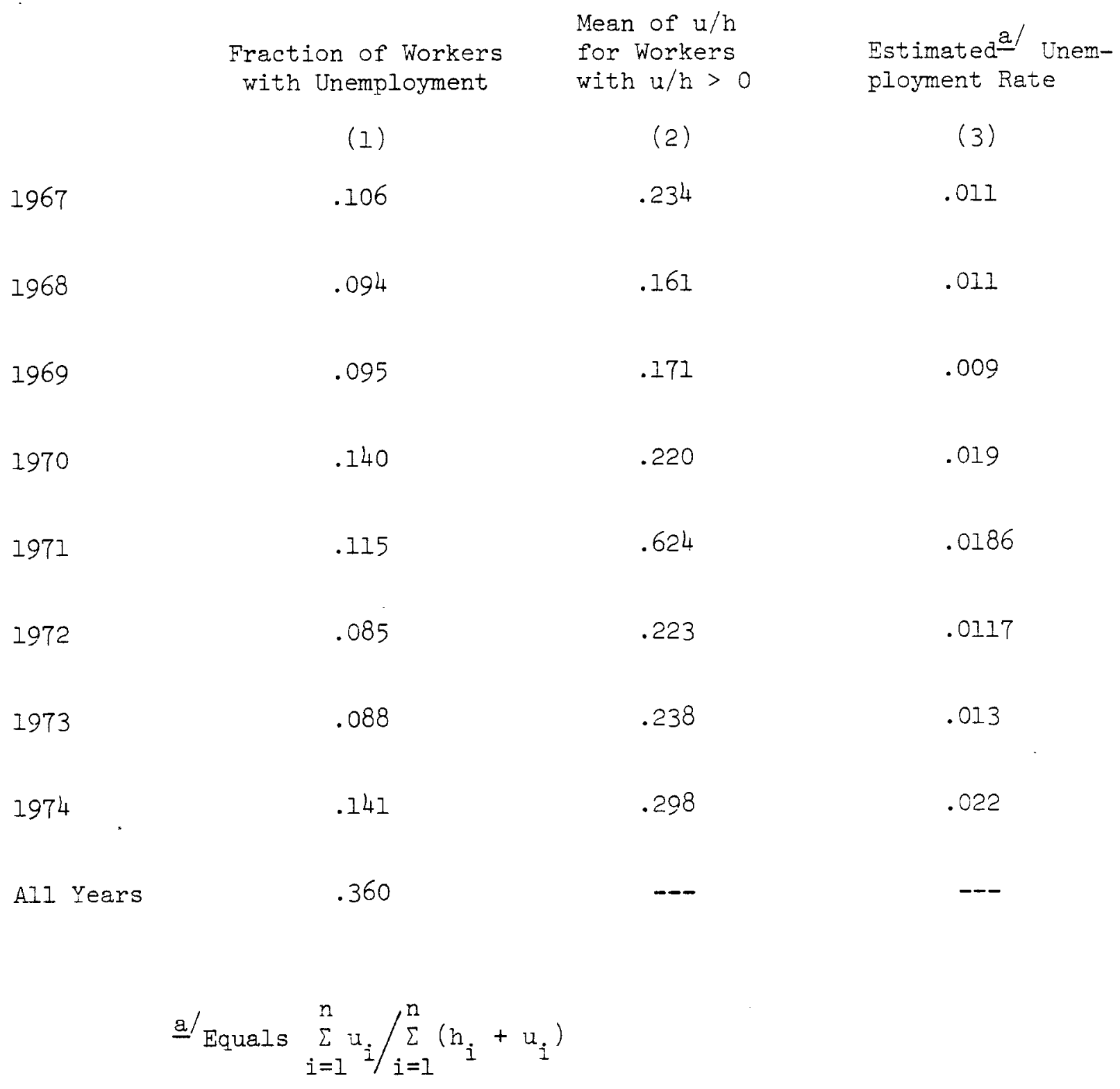


other, there are notable exceptions in 1967, 1971 and 1974. Table 2 also contains the maximum likelihood estimates of the effect of schooling on unemployment when the truncation of unemployment at zero hours is recognized for each of the eight years. All of these effects are negative and significantly different from zero, although again there is some variability in the estimated effects of schooling.

Although we do not speculate on the reasons for this variability in detail, Table 3 contains information on (1) the incidence and (2) the mean duration of unemployment for those workers with unemployment in each of the eight years that may be of some interest. The estimated unemployment rates in column 3 of the Table are somewhat lower than the conventional aggregate estimates of unemoloyment rates for this age group from the Current Population Survey. It is clear from this Table that movements in unemoloyment rates generally result from movements in both the incidence and duration of unemployment hours, even though this is not a sharp relationship. The higher unemployment rate in 1971 , for example, seems mainly to have been a result of a sharp increase in the duration of unemployment, while the higher unemployment rate in 1974 is a result of both a greater incidence and duration of unemployment. In any case the results in Tables 2 and 3 together do suggest that the discrepancy between the effects of schooling on earnings and wage rates may vary from year to year so that some care must be exercised in making comparisons between the results in Table 1 for an average of years with the results that other investigators obtain for a single year.

The results in Tables 2 and 3 suggest that the effects of schooling on unemployment may be lower (in absolute value) when, for a given unemployment rate, the duration of unemployment is high. To explore this issue in more detail we 
have estimated equations for the incidence and conditional duration or unemployment as functions of schooling and experience and its square, and placed the results in Table 4. The incidence function was estimated as a probit equation, while ordinary least squares was used to estimate the duration equation. 4 As can be seen from the Table, schooling has a strong effect on the incilence of unemployment, but virtually no effect on the duration of unemployment. 5/ On the other hand, experience has very little effect on the incidence of unemployment, but a somewhat stronger effect on the duration of unemployment. Although the relationship is below statistical significance at conventional test levels the duration of unemployment declines with experience to around $\hat{x}=17$ and then increases.

Table 5 reports the coefficients on schooling for equations comparable to those in Table 4 but fitted for each of the eight years in the sample. As can be seen from the Table these results indicate the same response of the incidence and duration of unemployment to schooling as the overall averages do in Table 4. There is a significant stable negative relationship between the incidence of unemployment in any year and schooling level, with the probability of having non-zero unemployment declining about .02 per year of schooling. Likewise, there is little evidence of a stable relationship between schooling and the duration of unemployment, with positive schooling coefficients in three years and negative schooling coefficients in five years.

4/ Since this equation is conditional on individuals havine a spell of unemployment, the ordinary least squares estimates may suffer from sample selectivity bias. We tested for the presence of selectivity bias using the approach suggested by Heckman (1979), but we could not reject the null hypothesis of no selectivity bias.

5/This last effect is apparently consistent with the findings of Kiefer and Neuman (1979), who attribute it to positive effects of schooling on both the mean wage offered unemployed workers and the mean reservation wage of unemployed workers. 


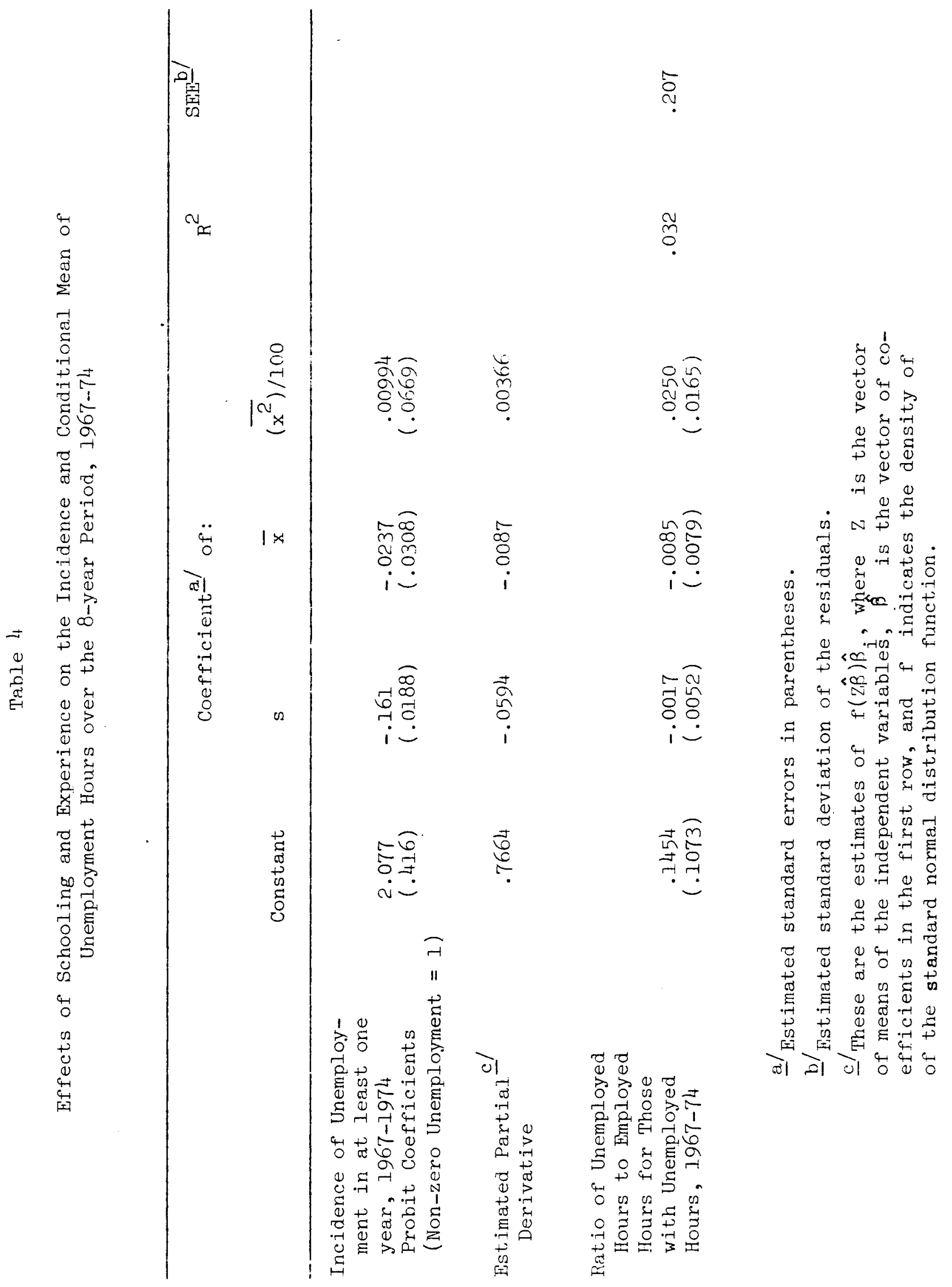


Table 5

Estimated Effects ${ }^{\text {a/ }}$ of Schooling on the Incidence of Unemployment and the Conditional Mean of Unemployment

Hours, 1967-74

$\underline{\text { Year }}$

1967

1968

1969

1970

1971

1972

1973

1974

All Years
Incidence (Probit: $\quad f(z \hat{\beta}) \underline{b} / \hat{\beta}$ )

$-.026 *$

$-.0196 *$

$-.0177^{*}$

$-.0225^{*}$

$-.0193^{*}$

$-.0159 *$

$-.0187^{*}$

$-.0327^{*}$

$-.0594 *$
Conditional Mean

$-.0035$

$-.0217^{*}$

$-.0196$

.0019

.1625

.0210

$-.0020$

$-.0278$

$-.0017$

a/ An * implies the absolute value of the estimated t-ratio was greater than 2.0 for the coefficient.

b/ Evaluated at sample mean of $\mathrm{Z}$. 
of course, the implications of these results for the causal mechanism by which schooling affects unemployment requires further research, but in the interim we turn next to the question of the extent to which workers behave as if they perceive the unemployment we have measured as a constraint on choice.

\section{Unemployment and Earnings}

In order to determine whether unemployment is a constraint on choice it is necessary to examine the extent to which the worker's stated unemployed hours are a part of the offer to sell labor. One way to do this is to compare the hours that it would be predicted the worker would supply to the market at current wages and prices against the hours he actually works in the unemployed periods and see how this difference compares with measured unemployed hours. $6 /$ The critical aspect of this process is specifying the determinants of labor supply in the absence of any unemployment.

A. Life-Cycle Labor Supply Without Unemployment

Although there are several ways to generate the functional form for labor supply (and comodity demand) functions, we have chosen to do so here by specifying an explicit utility function and obtaining the labor supply and commodity demand functions directly. The simplest functional form that has been even partially successful in this context is the so-called augmented Stone-Geary utility function. I/ In an intertemporal context this function is additive both at a point

6/An example of this procedure in an aggregate time-series context is contained in Ashenfelter (1977). Rae (1974) was one of the first authors to investigate this problem using cross-section data. A less rigid scheme is to implicitly compare hours supplied and hours worked as between those who do and do not claim to be constrained in their choices, but without obtaining (or using) quantitative information on the magnitude of the constraint. The econometric framework for this approach is pursued by Ham (1978).

I/ This was fitted to aggregate U.S. time-series data by Abbott and Ashenfelter (1976), for example. 
in time and over time. In particular, we start with the utility function

$$
\text { (5) } v=\sum_{t}(1+p)^{-t}\left[B_{1} \ln \left(\gamma_{h}-h_{t}\right)+B_{2} \ln \left(c_{t}-\gamma_{c}\right)\right]
$$

where $\rho, B_{1}, B_{2}, \gamma_{h}$, and $\gamma_{c}$ are parameters and $h_{t}$ and $c_{t}$ are hours of work and aggregate commodity consumption. In this setup there is a minimum necessary commodity consumption level $\gamma_{c}$, a maximum feasible hours of work level $\gamma_{h}$, and a rate of time preference $\rho$ that do not vary over time.

Maximizing (5) subject to the lifetime budget constraint

(6) $\sum_{t}(1+r)^{-t}\left[w_{t} h_{t}+y_{t}-p_{t} c_{t}\right]=0$,

with fixed interest rate $r$ and unearned income $y_{t}$ leads to the first-order conditions

$$
\begin{aligned}
& \text { (7a) } B_{I t}^{*} /\left(\gamma_{h}-h_{t}\right)=\lambda w_{t}^{*} \\
& \text { (7b) } B_{2 t}^{*} /\left(c_{t}-\gamma_{c}\right)=\lambda p_{t}^{*},
\end{aligned}
$$

where $\lambda$ is a Lagrange multiplier, $B_{i t}^{*}=B_{i}(I+\rho)^{-t}, i=I, 2, w_{t}^{*}=w_{t}(I+r)^{-t}$; and $p_{t}^{*}=p_{t}(1+r)^{-t}$. Solving $(7 a)$ and $(7 b)$ for the $B_{i t}^{*}$, summing the resulting equations and using (6) then establishes

$$
\text { (8) } \lambda=\sum_{t}\left(B_{I t}^{*}+B_{2 t}^{*}\right) / F^{*} \text {, }
$$

where

$$
\text { (9) } F^{*}=\sum\left(y_{t}^{*}+\gamma_{h} w_{t}^{*}-\gamma_{c} p_{t}^{*}\right)
$$

and $y_{t}^{*}=y_{t}(1+r)^{-t}$ as the explicit formula for the marginal utility of the discounted present value of expected unearned income or, alternatively, permanent unearned income. Analogously to the usual Stone-Geary case, F* may be thought of as the discounted present value of expected future "discretionary" income. In effect, $\sum\left(y_{t}^{*}+\gamma_{h} w_{t}^{*}\right)$ is maximum feasible earnings while $\sum \gamma_{c} p_{t}^{*}$ 
is minimum feasible consumption, and $F^{*}$ is merely the difference between them. The marginal utility of permanent unearned income is then seen to be proportional to the reciprocal of $F^{*}$.

It follows immediately from the substitution of (8) into (7a) that the desired labor earnings of the worker are

$$
\text { (10) } w_{t} h_{t}^{*}=\gamma_{h} w_{t}-\eta^{t} B_{1}^{*} F^{*}
$$

where $B_{1}^{*}=B_{1} / \Sigma\left(B_{1 t}^{*}+B_{2 t}^{*}\right)$ and $n=(1+r) /(1+p)$. In $(10)$ we have been careful to indicate that the dependent variable is the product of the wage rate in period $t$ and desired hours $h_{t}^{*}$ in period $t$. Equation (10) is a remarkable simplification, but we should remark on its limitations. 1 / First, it is based on an intertemporally additive specification of life-time utility. Since some have argued that the essence of the explanation of cyclical movements in labor supply is to be found in substantial intertemporal substitution in the demand for leisure it is important to recognize that the utility function (5) constrains the demand for leisure in different periods to be substitutes, but in a very special and limited way. $9 /$ Thus, the resulting specification of (10) may not be suitably unconstrained for the problem at hand. Second, the term $F^{*}$ depends critically on the way that expectations of future wages and prices are formed and thus it cannot be fit to the data without further specification. Finally, equation (10) has been derived independently of any considerations regarding the acquisition of

8/Equation (10) is a member of the class of what Heckman and MaCuray (1979) have called " $\lambda$ constant" Iife-cycle supply functions. It has properties analogous to those discussed by Hall (1978) in permanent income models of consumption.

$9 /$ For an explanation of unemployment as intertemporal substitution of leisure demanded see Lucas and Rapping (1969). 
human capital by workers over the life-cycle. It is well known that there are conditions on the nature of the acquisition of human capital under which this is permissible, but these are also known to be very restrictive.

B. Labor Supply in the Presence of Unemployment

In order to make equation (10) operational it is useful to consider two groups of workers in more detail. The first group suffers no unemployment during the life-cycle period (of eight years) under consideration. For these workers we will assume that, apart from the addition of a disturbance term to be specified below, equation (10) is a satisfactory description of the evolution of their labor supply.

A second group of workers includes those who state they encounter a spell of unemployment during some part of their longitudinal history. For these workers there are two inherent difficulties in applying equation (10) directly. First, there is the question of defining the desired labor supply for the periods when these workers are unemployed. To see the difficulty, suppose a worker encounters unemployment in two periods. Under these circumstances how does the worker perceive of his desired hours in the period in which the constraint is encountered? One possibility is that the worker defines his unemployment for a given period as the difference between his desired and actual hours in that period taking account of the extent of the unemployment in other periods. Alternatively: the worker may define his unemployment as the (negative of the) difference between actual hours and the hours he would have desired had he never encountered unemployment in any time period. Although the former approach has some appeal its implementation would be complicated and will have to await further research. $\frac{10 /}{1}$

10/ These issues are discussed, but not resolved, by Malinvaud (1977), especially pp. $22-25$. 
To proceed, therefore, we shall merely assume that $h_{t}$ represents an upper bound on hours worked in the periods of unemployment and that

$$
\text { (11) } h_{t}^{*}=h_{t}+\theta u_{t}=
$$

where $\Theta$ is defined as the fraction of unemployed hours that would have been offered to the market in the absence of unemployment in any period. Substituting (11) into (10) yields

$$
\text { (12) } w_{t} h_{t}=w_{t} \gamma_{h}-n^{t_{B}^{*} F^{*}}-e w_{t} u_{t} \text {. }
$$

It should be clear that the validity of (12) depends upon our assumption about the worker's interpretation of the meaning of $u_{t}$, unemployed hours.

Given the appropriate labor supply equation (12) for the periods with positive unemployment, we must next turn to determining the labor supply equation for the unconstrained periods for those workers who face unemployment at some point during their longitudinal experience. One possibility is simply to use (12) with $u_{t}=0$. This is one of the procedures that we use below, and we call this Model I. Apart from its simplicity, the advantage of this procedure is that it is clearly the correct model structure under the null hypothesis $\theta=0$. It may therefore serve as a useful framework for testing this hypothesis. The disadvantage of this procedure is that by using it we are implicitly assuming that spells of unemployment are unanticipated and that the life-cycle labor supply behavior of those workers who encounter such spells is subsequently unaffected. Workers who face anticipated constraints in some periods would generally choose their labor supply in unconstrained periods so as to maximize their utility conditional on the hours worked in the constrained periods. This process will, of course, lead to a different labor supply function than (10). 
To consider the utility maximization problem in the presence of anticipated constraints assume that the worker knows he will be constrained at $\bar{h}_{t}$ hours in certain periods $R$, and thus maximizes utility with respect to his labor supply in the unconstrained periods $N R$ and with respect to his consumption in all periods. More formally, the worker now maximizes

$$
\text { (13) } \begin{aligned}
\mathrm{v}^{*} & =\sum_{t \varepsilon N R}(I+p)^{-t} B_{I} \ln \left(\gamma_{h}-h_{t}\right)+\sum_{t \varepsilon R}(I+p)^{-t} B_{I} \ln \left(\gamma_{h}-\bar{h}_{t}\right) \\
& +\sum_{t}(I+p)^{-t} B_{2} \ln \left(c_{t}-\gamma_{c}\right)
\end{aligned}
$$

subject to the new lifetime budget constraint

$$
\text { (14) } \sum_{t \in N R}(I+r)^{-t}\left[w_{t} h_{t}+y_{t}-p_{t} c_{t}\right]+\sum_{t \in R}(I+r)^{-t}\left[w_{t} \bar{h}_{t}+y_{t}-p_{t} c_{t}\right]=0 \text {. }
$$

The first order-conditions for this problem may be written

$$
\begin{aligned}
& \text { (15a) } B_{1 t}^{*} /\left(\gamma_{h}-h_{t}\right)=\lambda w_{t}^{*} \quad t \varepsilon N R \\
& (15 b) \quad B_{2 t}^{*} /\left(c_{t}-\gamma_{c}\right)=\lambda p_{t}^{*} \quad \text { all } t,
\end{aligned}
$$

where again $\lambda$ is a Lagrange multiplier, $B_{i t}^{*}=B_{i}(I+p)^{-t}, i=I, 2, w_{t}^{*}=w_{t}(I+r)^{-t}$ and $p_{t}^{*}=p_{t}(1+r)^{-t}$. Solving $(15 a)$ and $(15 b)$ for $B_{i t}^{*}$, summing the resulting equations and using the budget constraint (14) establishes

$$
\begin{aligned}
\text { (16) } \lambda=\left(\sum_{t \in N R} B_{I t}^{*}+\sum_{t} B_{2 t}^{*}\right) / \tilde{F} \quad \text { where } \\
\text { (17) } \tilde{F}=\sum_{t} y_{t}^{*}+\sum_{t \varepsilon N R} w_{t}^{*} \gamma_{h}+\sum_{t \in R} w_{t}^{*} \bar{h}_{t}-\sum_{t} p_{t}^{*} \gamma_{c}
\end{aligned}
$$

and $y_{t}^{*}=y_{t}(1+r)^{-t}$. 
The new discretionary income term $\tilde{F}$ differs from the expression $F^{*}$ above because of the reduction in maximum feasible earnings of $\sum_{t \varepsilon R}\left(\hat{\gamma}_{h}-\bar{h}_{t}\right) w_{t}^{*}$ caused by the constraints $\bar{h}_{t}$. Substituting (16) into (15a) shows that desired earnings are

$$
\text { (18) } w_{t} h_{t}=w_{t} \gamma_{h}-\eta{ }^{t} \tilde{B}_{I} \tilde{F} \quad \text { teNR }
$$

where $\tilde{B}_{1}=B_{1} /\left(\sum_{t \varepsilon \mathbb{N R}} B_{1 t}^{*}+\sum_{t} B_{2 t}^{*}\right)$ and $\eta=(I+r) /(I+p)$. iy comparing ( $I \hat{\prime})$ to the earnings equation when there are no constraints, (10), we see that the worker encountering unemployment in his life cycle now allocates a larger share of his discretionary income to leisure $\left(\tilde{B}_{1}>B_{1}^{*}\right)$ during periods when he may choose his labor supply, but that he now has a smaller discretionary income to allocate, $\left(\tilde{F}<F^{*}\right)$. The combination of equations (12) and (18) we shall call Model II. As it turns out, Model I is nested as a special case of Model II and this affords the possibility of testing between the two.

\section{Empirical Results}

In order to proceed to the estimation of Models I and II we must specify both the way in which expectations of wages and prices are determined and an appropriate form for the disturbance terms. One especially simple specification embodies the hypothesis that current and future wages and prices are known with certainty and that the error terms appended to (12) and (18) contain a fixed effect for the individual and a serially uncorrelated random effect. Model I may then be written

$$
\text { (12a) } w_{i t} h_{i t}=\gamma_{h} w_{i t}-\eta^{t} \beta_{1}^{*} F_{i}^{*}-\theta w_{i t} u_{i t}+\varepsilon_{i}+\varepsilon_{i t} \text { all } t \text {. }
$$


Denoting the individuals who encounter no unemployment in their life cycles by $\mathbb{N}$, we may then write the appropriate earnings equations for Model II in the compact form

$$
\begin{array}{lll}
\text { (12b) } w_{i t} h_{i t}=\gamma_{h} w_{i t}-\eta{ }^{t} B_{I}^{*} F_{i}^{*}-\theta_{i t} u_{i t}+\varepsilon_{i}+\varepsilon_{i t}, & t \varepsilon R, \mathbb{N} \\
\text { (18a) } w_{i t} h_{i t}=\gamma_{h} w_{i t}-\eta{ }^{t} \tilde{B}_{l i} \tilde{F}_{i}+\varepsilon_{i}+\varepsilon_{i t}, & t \varepsilon N R
\end{array}
$$

These are models with nonlinear restrictions that may be estimated by nonlinear regression methods.

As is well known, fitting Models I and II to longitudinal data is equivalent to adding dummy variables for each individual in the sample to the equation. $\frac{11 /}{}$ Consequently, other unchanging variables that might affect tastes for work or the propensity to incur unemployment are implicitly controlled. This is especially important when considering the role of unemployment in this framework since it is known that some groups of workers enter occupations or have other characteristics that may effect the permanent component of their unemployed hours. In effect, therefore, the coefficient $\Theta$ reflects the effects of variation of unemployed hours only within the experience of individual workers and not the differences in unemployment between them. $12 /$

Table $\dot{6}$ contains the results of fitting Models I and II to the data for

II/See Mundlak (1978).

12/ The only other attempt to do this of which we are aware is due to Roger Gordon (1976). An alternative approach is to treat the $\varepsilon_{\text {i }}$ as a random component of the error term. This could lead to an increase in efficiency, but at the risk of simultaneous-equations bias, if the permanent component of the error term is correlated with the independent variables. 
Table 6

Estimates of Life-Cycle Labor Supply Model from Longitudinal Data for 1967-74 with Fixed Effects Errors, Estimated Standard Errors in Parentheses

\begin{tabular}{cccccc}
\hline $\begin{array}{c}\text { Line } \\
\text { Number }\end{array}$ & Estimate of & Sum of & & $R^{2}$ \\
\hline
\end{tabular}

Model I

\begin{tabular}{|c|c|c|c|c|c|}
\hline 1 b/ & $\begin{array}{l}1886.75 \\
(14.729)\end{array}$ & $\begin{array}{l}.9276 \\
(.0200)\end{array}$ & 1.0 & $2.78098 \times 10^{10}$ & $.922^{a} /$ \\
\hline 2 l & $\begin{array}{c}1545.24 \\
(15.608)\end{array}$ & $\begin{array}{l}.7807 \\
(.0147)\end{array}$ & $\begin{array}{l}1.376 \\
(.0207)\end{array}$ & $1.464229 \times 10^{10}$ & .959 \\
\hline
\end{tabular}

Model II

$\begin{array}{cccccc}1895.83 & .9319 & 1.0 & 2.69373 \times 10^{10} & .924 \text { al } \\ & (15.157) & (.0227) & & & \\ & & & & & \\ 1589.45 & (15.680) & (.0157) & (.0223) & 1.35614 \times 10^{10} & .962\end{array}$

a/ This is $\mathrm{R}^{2}$ before the removal of the fixed effects.

- The $R^{2}$ after the removal of the fixed effects was .746 and .747 in lines 1 and 3 respectively.

b/ Test statistic for comparing lines $I$ and 3 is $F(288,5303)=.5966$

c/ Test statistic for comparing lines 2 and 4 is $x^{2}(288)=490.195$. Critical value of $x^{2}(288)$ at .005 level is approximately $353.5 \varepsilon$.

Dependent variable: annual earnings in dollars.

Mean of dependent variable: 12,322.

Sum of squared residuals of dependent variable around mean: 3.56449 $x 10^{11}$.

Number of individuals: 799. Number of observations: 6392.

Number of individuals with non-zero unemployment: 288. 
white male workers described in the preceding section. In lines 1 and 3 we arbitrarily specified $n=I$ for Models $I$ and II, respectively. For Model I this implies that the terms $B_{I}^{*} F_{i}^{*}$ become fixed effects for the $i \frac{\text { th }}{\text { individual }}$ and that $\varepsilon_{i}$ is no longer identified. For Model II this implies that the terms $B_{I}^{*} F_{i}^{*}$ and $\tilde{B}_{I i} \tilde{F}_{i}$ become separate fixed effects in the constrained and unconstrained periods for the $i$ th individual and that $\varepsilon_{i}$ is no longer identified. As can be seen from Table $6, \theta$ is estimated at .93 for both models. Although the hypotheses $\theta=0$ and $\theta=1$ may be firmly rejected in both models, the high value for $\theta$ implies that unemployed hours are mainly a part of the offer to sell labor. Finally, with the constraint $\eta=1$ Model II differs from Model I only in having separate fixed effects for constrained and unconstrained periods for workers with non-zero unemployment. Testing Model II against Model I simply involves a comparison of goodness of fit under these alternative specifications, and, as can be seen from Table 6 , the simpler specification of Model I clearly cannot be rejected.

In lines 2 and 4 of Table 6 we have placed the results of relaxing the constraint $\cdot n=1$ and estimating Models $I$ and II by nonlinear least squares. $\frac{13 /}{}$

$13 /$ The fixed effects $\varepsilon_{i}$ and the terms $B_{1}^{*} F_{i}^{*}$ and $\tilde{B}_{I i} \tilde{F}_{i}$ were minimized out of the sum of squared residuals in Model II in the following manner. Assume $Y_{\text {, }}, \eta$ and $\theta$ are known. Let $y_{i t}=w_{i t} h_{i t}-w_{i t} \gamma_{h}+\theta_{i t} u_{i t}, x_{i t}=n^{t} \delta_{j}$ and $z_{i t}=n^{t}\left(h_{i} \delta_{i}\right)$, where $\delta_{i}=1$ if $t \varepsilon R, N$ and zero otherwise. Equations ( $12 b$ ) and (18a) may then be written compactly as $y_{i t}=\varepsilon_{i}-\left(B_{I}^{*} F_{i}^{*}\right) x_{i t}-\left(\tilde{B}_{i i_{i}} \tilde{F}_{i t}+\varepsilon_{i t}\right.$. The terms $\varepsilon_{i}, B_{i}^{*} F_{i}^{*}$ and $\widetilde{B}_{1 i} \widetilde{F}_{i}$ can be estimated by computing a regression and this provides a method for calculating the minimum sum of squared residuals conditional on $\gamma_{h}, \eta$ and $\theta$. To find the minimum sum of squared residuals for all parameters, we used the Davidon-Fletcher-Powell algorithm from Powell (1971) to minimize the function with respect to $\gamma_{h}, \eta$ and $\theta$, mimimizing out the individual parameters on each function evaluation. This provides a relatively inexpensive method for estimating a fixed effect nonlinear least-squares model. Since Model $I$ is a special case of Model II, the terms $\varepsilon_{i}$ and $B_{1}^{*} F_{i}^{*}$ may be minimized out of the sum of squared residuals in Model $I$ by computing the above regression with $B_{I}^{*} F_{i}^{*}$ constrained to equal $\widetilde{\mathrm{B}}_{I i} \tilde{\mathrm{F}}_{i}$. 
Here the estimate of $\theta$ is around .78 for both models. Again the hypotheses $\theta=0$ and $\theta=1$ may be firmly rejected for both models, but the implication remains that some three-quarters of unemployed hours appear to be part of the offer to sell labor. Without the constraint $n=1$ a chi-square test rejects Model I in favor of the alternative Model II, but, as can be seen from Table 6, there is little basis for choosing between them at an empirical level.

The result of this estimation is relatively strong evidence that some unemployed hours represent real constraints on labor market choices and are not simply the result of those choices. Nevertheless, the labor supply functions in Table 6 are far from satisfactory and their poor quality clearly prohibits these tests from being entirely convincing. First, the estimates of $\gamma_{h}$ in Table 6 are unacceptably low, being less than observed hours for many workers in the sample. This means that the underlying supply parameters do not obey the classical restrictions and is clearly cause for further research. Second, the estimate of $\eta$, although consistent with positive savings for this group, seems unacceptably high since it implies a lower bound for $r$ of around.4. This is also cause for additional research. .

Perhaps the most promising avenue for future research is to recognize explicitly that unemployment and the expectation of its persistence must be built explicitly into our models of labor supply. By failing to do this we ignore the fact that $u_{t}$ is perhaps endogenous, and because the choice of (12) or (18) depends on the presence of non-zero values of $v_{t}$, these equations will suffer from sample selectivity bias, as well as the ordinary simultaneous equations bias in (12). Dealing with this issue explicitly is an important area for future research. 
Conclusion

Our results suggest that the excess of the marginal effects of schooling and experience on earnings over their effects on wage rates is due almost entirely to the effect of schooling and work experience in reducing measured unemployment. Schooling produces this effect on unemployment solely by reducing the incidence of unemployment spells among the workers in our sample while work experience does this mainly by reducing the duration of unemployment spells amongst those workers who have such spells. Of course, this does not imply that increased educational attainment will necessarily reduce the aggregate of unemployment because the effect we observe may come merely from a redistribution of unemployment among workers. On the other hand, there is certainly no presumption to the contrary. The problems here are no different than the problems of discovering whether increased educational investments for individual workers merely redistribute wage income rather than increasing its aggregate, and they can probably only be addressed in an aggregate time series context, if at all.

We also find that a considerable fraction of measured unemployment hours behavesas if it was primarily a part of the offer to sell labor and does, therefore, represent real constraints on choice. It follows that eaucational investments do relax the constraints on choice that workers face in the labor market, but whether these are merely private or also social gains cannot be determined without further research. 


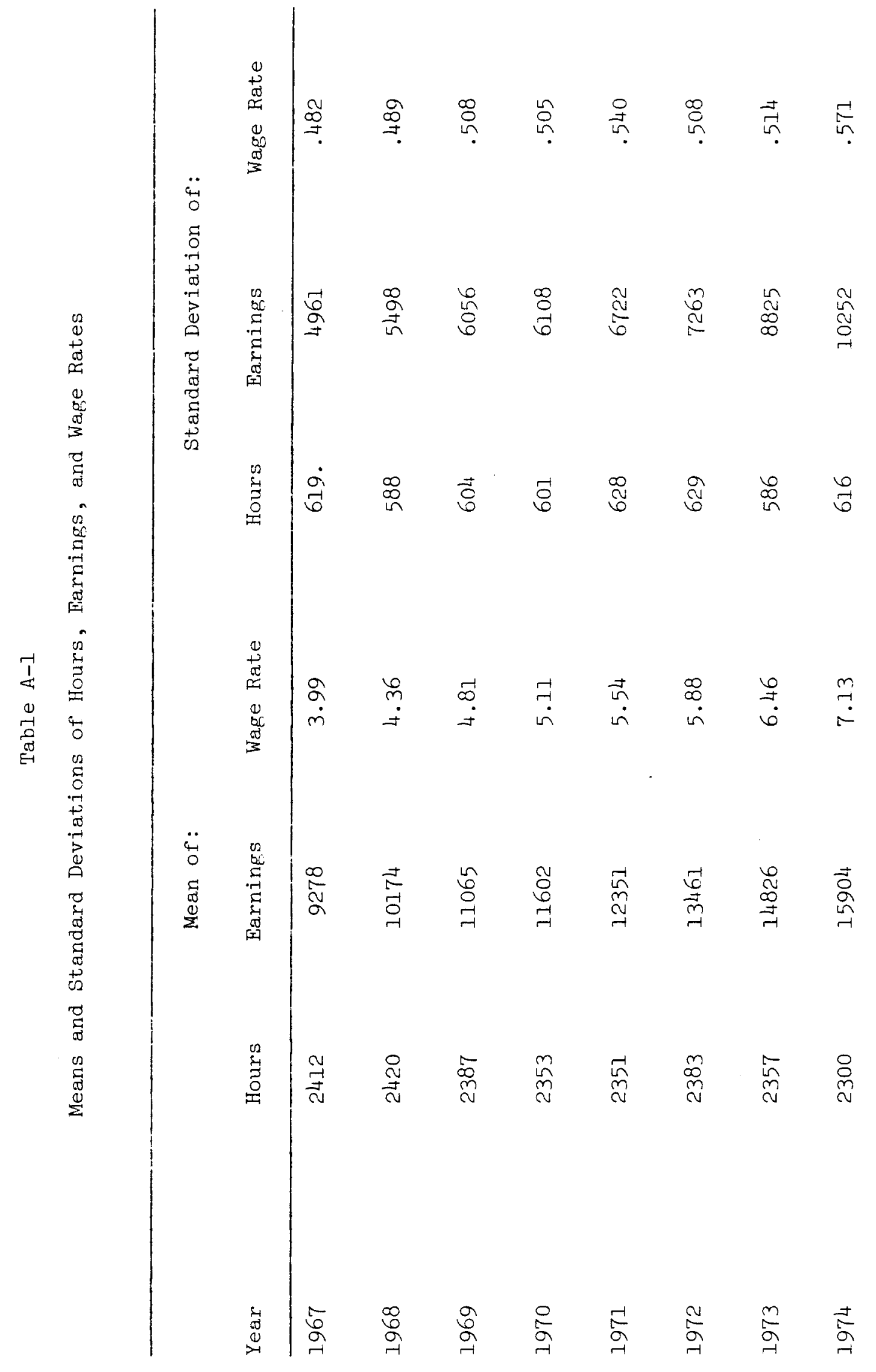


Abbott, M., and Ashenfelter, Orley. "Labour Supply, Commodity Demand, and the Allocation of Time." Review of Economic Studies 42 (October 1976): $389-411$.

Ashenfelter, Orley. "Unemployment as Disequilibrium in a Model of Aggregate Labor Supply." Princeton University, Industrial Relations Section, Working Paper No. 104, November 1977.

Gordon, R.H. Essays on the Causes and Equitable Treatment of Differences in Earnings and Ability. Ph.D. Thesis, Massachusetts Institute of Technology, June 1976.

Hall, Robert E. "Stochastic Implications of the Life Cycle-Permanent Income Hypothesis: Theory and Evidence." Journal of Political Economy, No. 6 (December 1978): 971-87.

Ham, John. "Rationing and the Supply of Labor: An Econometric Approach." Industrial Relations Section, Princeton University, Working Paper No. 103A, August 1978.

Heckman, James J. "Sample Selection Bias as a Specification Error." Econometrica 47 (January 1979): 153-162.

and MaCurdy, T. "A Life Cycle Model of Female Labor Supply." Unpublished paper, January 1979.

Kiefer, Nicholas M., and Neumann, George R. "An Empirical Job-Search Model, with a Test of the Constant Reservation-Wage Hypothesis." Journal of Political Economy, 87, No. I (February 1979): 89-107.

Lucas, Robert E., Jr., and Rapping, Leonard A. "Real Wages, Employment, and Inflation." Journal of Political Economy 77, No. 5 (September/October 1969): $721-54$.

Malinvaud, E. The Theory of Unemployment Reconsidered. New York: Halsted Press, 1977 .

Mincer, Jacob. Schooling, Experience, and Earnings. New York: National Bureau of Economic Research, 1974.

Mundlak, Yair. "On the Pooling of Time Series and Cross Section Data." Econometrica 46 (January 1978): 69-86.

Powell, M. J.D. "Recent Advances in Unconstrained Optimization." Mathematical Programming 1 (October 1971): 26-57.

Psacharopoulos, George, and Layard, Richard. "Human Capital and Earnings: British Evidence and a Critique." Unpublished paper, Centre for Labour Economics, Iondon School of Economics, November 1977. 
Rae, S., "Unemployment and the Supply of Labor." Journal of Human Resources 9 (Spring 1974): 279-289.

Tobin, James. "Estimation of Relationships for Limited Dependent Variables." Econometrica 26 (January 1958): $24-36$. 